\title{
Morphological Changes in the Hypothalamic-Hypophyseal-Gonadal Axis of Male Rats After Twelve Months of Streptozotocin-Induced Diabetes
}

\author{
G. L. Rossi and G. Bestetti \\ Institute of Animal Pathology, University of Berne, Switzerland
}

Summary. The hypothalami, pituitaries and testes from streptozotocin-treated and control male Wistar rats were examined by light and electron microscopy 12 months after induction of diabetes. Light and electron microscopic immunohistochemical techniques were employed for the localization of luteinizing hormone-releasing hormone and luteinizing hormone in the hypothalami and the pituitaries. In the hypothalami of diabetic animals swollen neuronal processes containing anti-luteinizing hormone-releasing-hormone positive material were frequent. In the pituitaries of the same animals a large number of small luteinizing hormone-gonadotrophs was found. These cells contained numerous secretory granules and were deficient in endoplasmic reticulum. The average testicular weight of the diabetic rats was significantly reduced but with marked individual variations. Histologically, the testes with the highest weights appeared normal, those with the lowest weights atrophic with few degenerating Leydig cells. These hypothalamic-hypophyseal changes are probably responsible for the testicular lesions found in experimental diabetes mellitus and may have relevance to the problem of infertility in human diabetes.

Key words: Streptozotocin diabetes, hypothalamus, pituitary, testes, morphology, immunohistochemistry, LH, LHRH.

Impaired reproductive function in both male human diabetics and comparable animal models has been known for many years [7]. It was suggested by early investigators that structural abnormalities of the testes may be due to hypophyseal gonadotrophic dysfunction $[5,14]$. During the last decade the hypothalamus- pituitary system in diabetic hypogonadism has received major attention $[3,4,7-10]$.

In a recent morphological study on the hypothalamus of male rats one year after induction of diabetes by streptozotocin, we described lesions in the arcuate nucleus and median eminence [1]. Following a preliminary investigation on the testes of the same animals, we found various degrees of testicular change [12]. In order to investigate further the possible relationship between these two findings [1, 12], we have performed a systematic light and electron microscopic study of the hypothalami, pituitaries and testes of rats after one year of streptozotocin-induced diabetes. Immunohistochemical identification of luteinizing hormone $(\mathrm{LH})$ and luteinizing hormone-releasing hormone $(\mathrm{LHRH})$ was also carried out on semi-thin and thin sections of the pituitaries and hypothalami.

\section{Materials and Methods}

Male Wistar rats of the Füllinsdorf strain, initially $100 \mathrm{~g}$ body weight were used. Streptozotocin solution in saline, adjusted to $\mathrm{pH}$ 4.5 with citrate buffer, was injected in the tail vein as a single dose of $6 \mathrm{mg} 0.2 \mathrm{ml} / 100 \mathrm{~g}$ body weight. A group of non-injected animals served as control. After 1 week blood glucose levels were measured (Dextrostix, Ames, Slough, UK) and rats with a glucose value of $9.7 \mathrm{mmol} / 1(175 \mathrm{mg} / 100 \mathrm{ml})$ or more were considered diabetic. The animals of each group were maintained two per cage under standard dietary and environmental conditions for the 12 month duration of the experiment.

Under urethane anaesthesia ( $150 \mathrm{mg} / 100 \mathrm{~g}$ body weight IP) a blood sample for glucose determination (Gluco-quant, Bochringer, Mannheim, FRG) was obtained from the jugular vein (Table 1). Whole-body perfusion-fixation with $2 \%$ glutaraldehyde- $1.5 \%$ para-

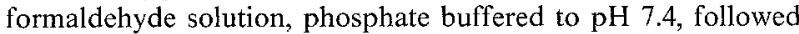
[11]. After $10 \mathrm{~min}$ of perfusion, the organs were isolated and left in the fixative solution for at least $48 \mathrm{~h}$.

Tissues from seven control and seven diabetic animals were used for the structural study. Hypothalami and pituitaries from 14 
other rats (seven control and seven diabetic) were used for the immunohistochemical localization of LHRH and LH.

Frontal sections, about $1 \mathrm{~mm}$ thick, were obtained from the hypothalami as previously described [1]. Paramedial sagittal sections, about $1 \mathrm{~mm}$ thick, were cut free-hand from the pituitaries as previously described [13]. From the testes, cross sections, about $2 \mathrm{~mm}$ thick, were cut and divided into four sectors. The blocks of tissue used for the morphological study were post-fixed in $2 \%$ osmium tetroxide solution ( $\mathrm{pH} \mathrm{7.4)}$ ) for $2 \mathrm{~h}$. The blocks of tissue used for immunohistochemistry were not post-fixed. After dehydration, tissues were infiltrated and embedded in Spurr's low viscosity medium.

For light microscopic study semi-thin sections were cut and stained with Toluidine blue. Subsequently, from selected areas of the same blocks, thin sections were cut, stained for contrast with uranyl acetate and lead citrate, and studied by electron microscopy.

Table 1. Final body and testes weights and blood glucose of control and diabetic rats (mean \pm SEM)

\begin{tabular}{lllll}
\hline & $\begin{array}{l}\text { No. of } \\
\text { rats }\end{array}$ & $\begin{array}{l}\text { Body weight } \\
(\mathrm{g})\end{array}$ & $\begin{array}{l}\text { Blood glucose } \\
(\mathrm{mmol} / \mathrm{l})\end{array}$ & $\begin{array}{l}\text { Testes } \\
(\mathrm{g})\end{array}$ \\
\hline Controls & 24 & $517 \pm 9.0$ & $8.56 \pm 0.30$ & $\begin{array}{l}3.70 \pm 0.06 \\
(3.18-4.52)\end{array}$ \\
Diabetics & 26 & $228 \pm 10.5$ & $29.67 \pm 0.87$ & $\begin{array}{l}2.79 \pm 0.19^{\mathrm{a}} \\
(0.20-3.98)\end{array}$ \\
\hline
\end{tabular}

$\overline{{ }^{a} p<0.01 \text { diabetic versus control animals (analysis of variance) }}$ Figures in parentheses $=$ range
Immunohistochemical localization of LH in the pituitary and of LHRH in the hypothalamus was performed on semi-thin and thin sections respectively for light and electron microscopy. Rabbit anti-bovine LH (UCB-Christaens Société Anonyme, Brussels, Belgium) and rabbit anti-LHRH (Immuno-Nuclear Corporation, Stillwater, Minnesota, USA) sera were purchased commercially. Both semi-thin and thin sections were pretreated with Mayor's reagent [6] to partially remove the polymerized plastic. For light microscopy, anti-LH and anti-LHRH sera were diluted $1: 1000$, for electron microscopy, they were diluted $1: 500$. Conjugation with peroxidase-antiperoxidase complex (Miles Laboratories, Elkhart, Indiana, USA) was performed according to Sternberger et al. [15]. Specificity controls were obtained by substituting primary antisera with normal rabbit serum.

The electron microscopic examination of thin sections stained either for contrast or immunohistochemically was carried out respectively at 60 or $40 \mathrm{KV}$, using a Philips EM 300 electron microscope.

\section{Results}

\section{Hypothalamus}

By light microscopic study of Toluidine blue stained semi-thin sections, vesicles of various size were constantly seen in the arcuate nucleus and median eminence of all diabetic animals (Fig. 2 a). These vesicles appeared to correspond to the swollen neuronal pro-
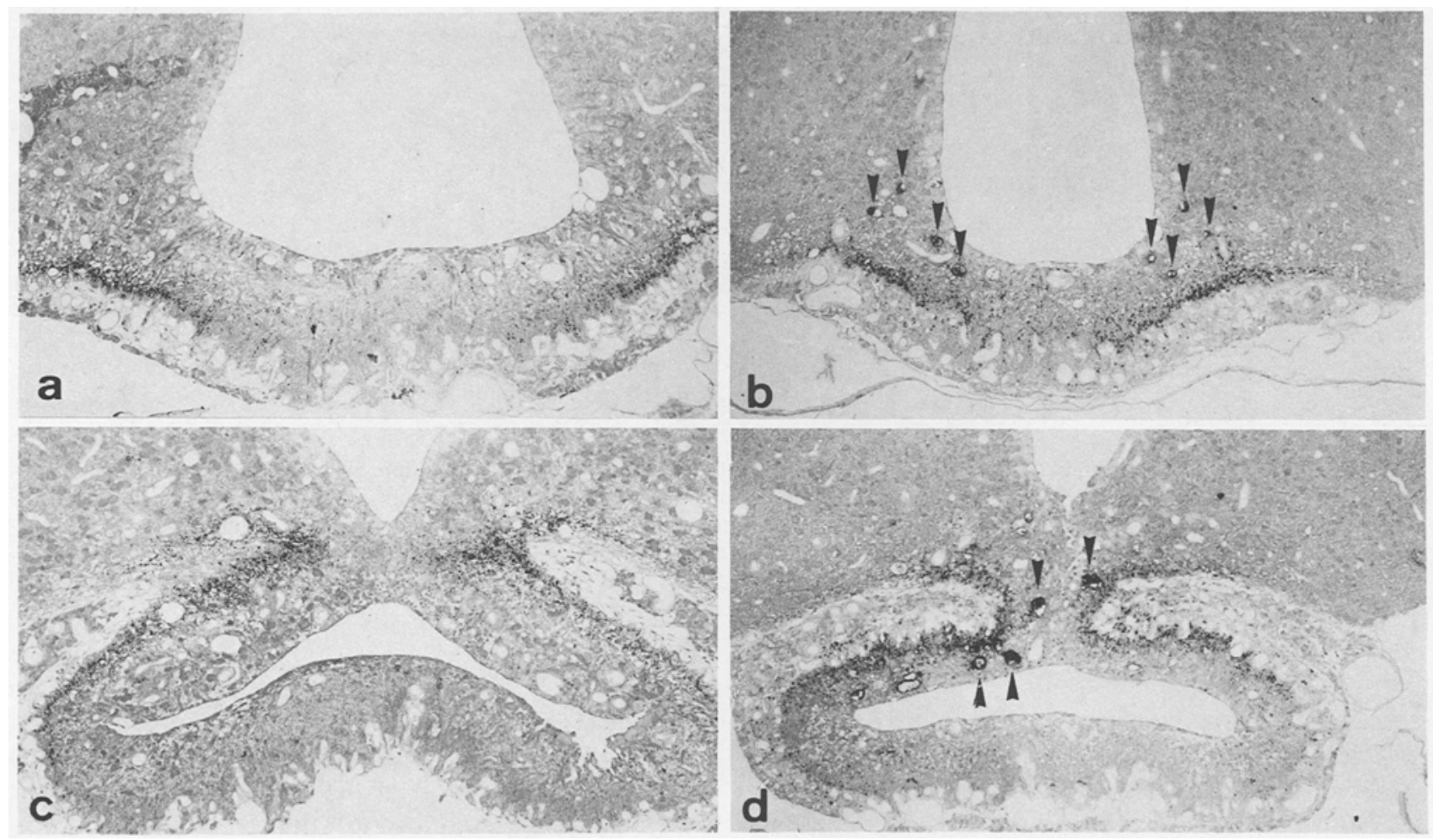

Fig. 1 a-d. Frontal sections through the medial $(\mathbf{a}, \mathbf{b})$ and posterior $(\mathbf{c}, \mathbf{d})$ hypothalamus of control $(\mathbf{a}, \mathbf{c})$ and diabetic (b, d) rats. Semi-thin sections, anti-LHRH/peroxidase-antiperoxidase reaction. Numerous labelled vesicles ( $A$ ) are present in diabetics. $104 x$ 

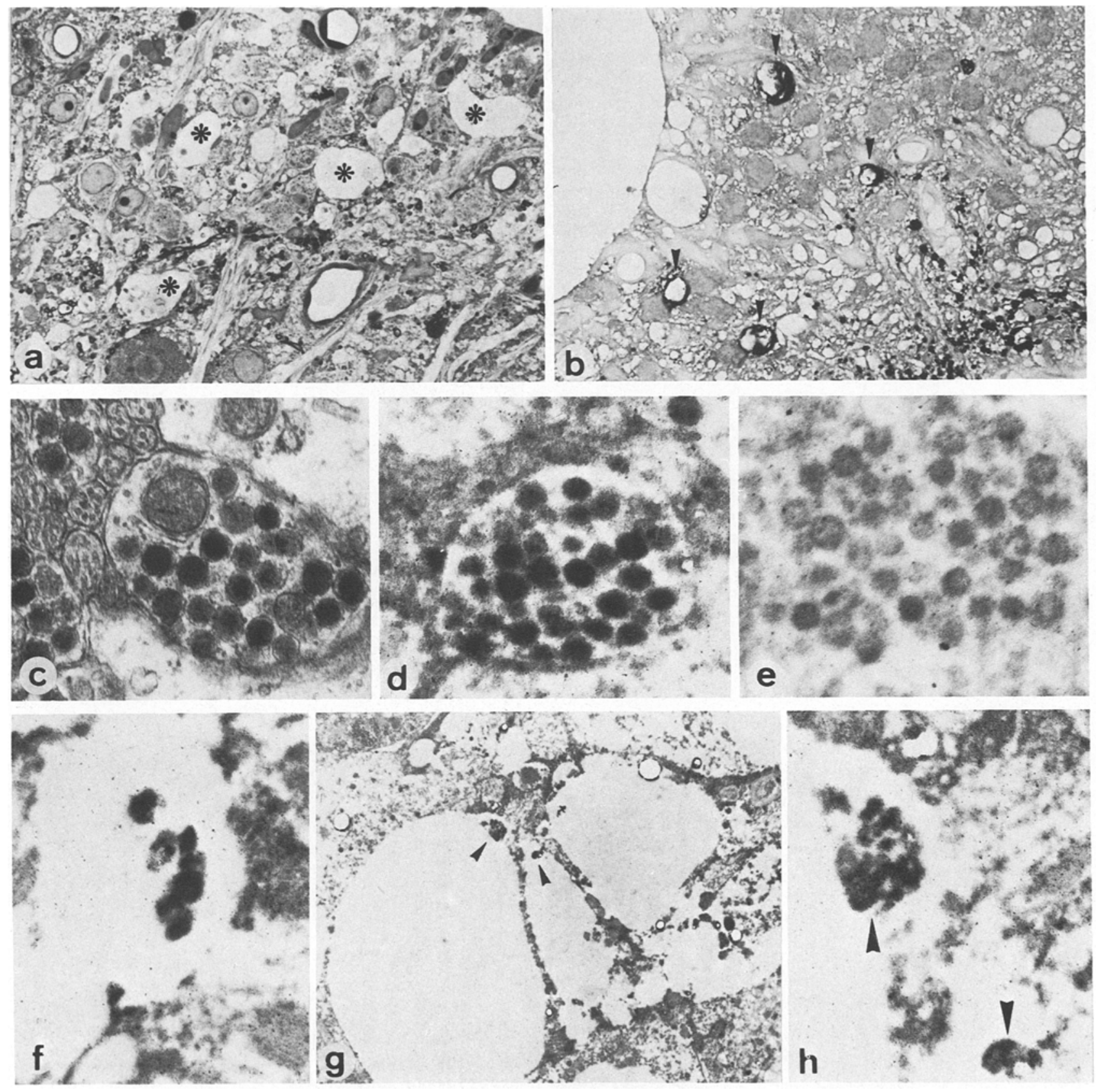

Fig. 2a-h. Frontal sections through the hypothalamus of diabetic rats. (a) Semi-thin section, Toluidine blue stain: some swollen neuronal processes $(*)$ are shown, $530 \times$.(b) Semi-thin section, anti-LHRH/peroxidase-antiperoxidase reaction: vesicles (A) containing positive material, $530 \times$. (c-e) Electron micrographs of axons containing conventionally stained neurosecretory granules (c), granules of comparable size stained by anti-LHRH/peroxidase-antiperoxidase reaction (d) and specificity control (e). 44,000×. (f) Axon containing anti-LHRH positive granules which appear to fuse and partially disintegrate. $35,500 \times$. (g-h) Electron micrographs of vesicles containing detritus and anti-LHRH positive material $(\boldsymbol{A})$ at low magnification $(\mathrm{g})$ and in detail $(\mathbf{h}) .6,900 \times, 34,500 \times$

cesses we previously reported [1]. Size and number of vesicles varied from animal to animal. No vesicle was observed in control rats.

Both control and diabetic animals had comparable amounts of anti-LHRH positive granules as determined by immunohistochemical study of semi-thin sections (Fig. 1a-d). In diabetics, however, antiLHRH positive material (Fig. 1 b, d and Fig. 2 b) was detected also in most of the above-mentioned vesicles. By electron microscopy, numerous axonal structures in the arcuate nuclei and median eminence of both control and diabetic animals contained neuro- 


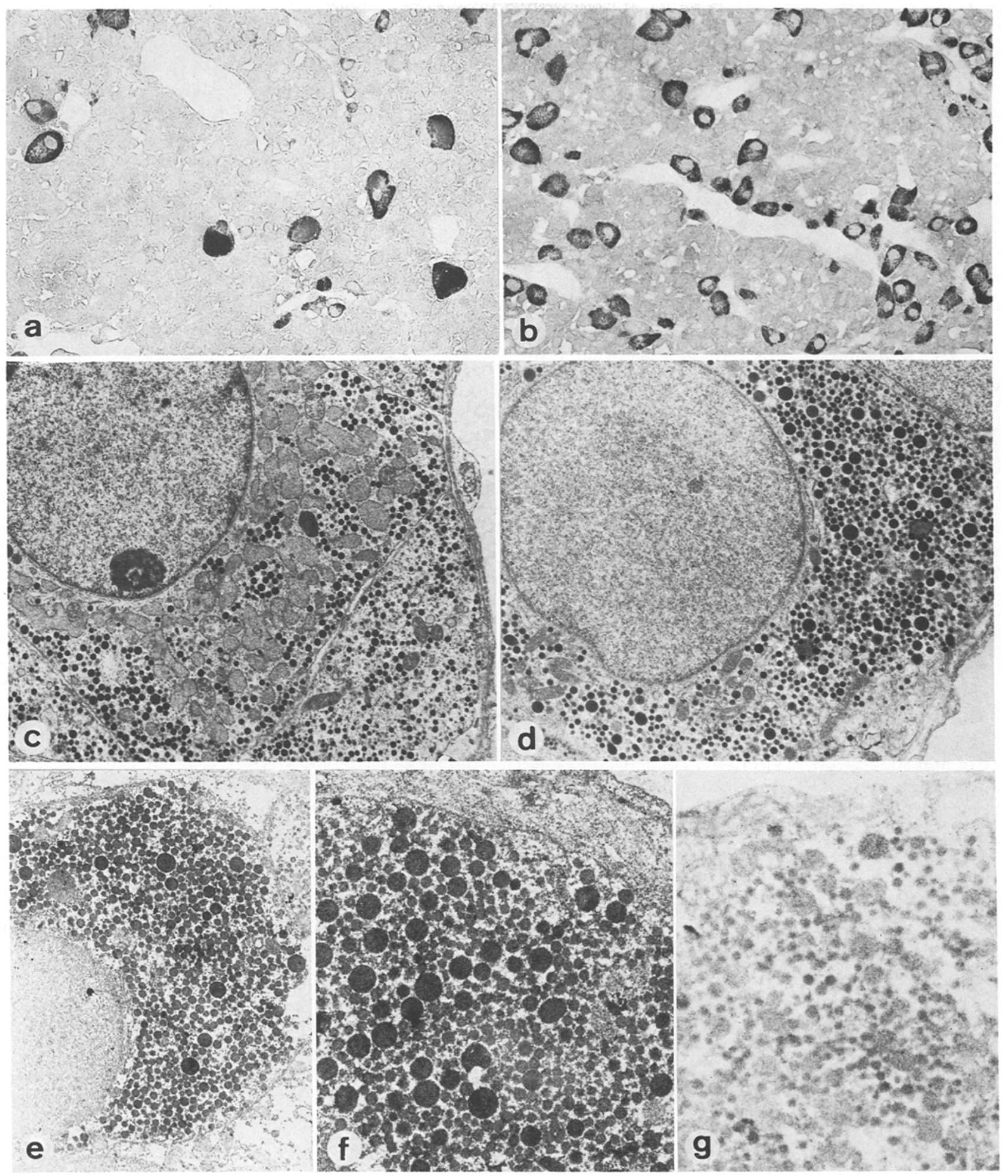

Fig. 3a-g. Pituitary gland of control $(a, c)$ and diabetic $(b, d-g)$ rats. $(a, b)$ Semi-thin sections, anti-LH/peroxidase-antiperoxidase reaction. Gonadotrophs in diabetics (b) are smaller and more numerous than in controls (a). $330 \times$. (c, d) Electron micrographs of gonadotrophs from a control (c) and a diabetic (d) animal; the cell from the diabetic contains almost no endoplasmic reticulum and a large number of secretory granules. 6,900 $\times$. $(\mathrm{e}-\mathrm{g})$ Electron-micrographs of gonadotrophs from a diabetic rat after anti-LH/peroxidase-antiperoxidase reaction at low magnification (e) and in detail (f) compared with the specificity control (g). $6,900 \times, 14,800 \times, 14,800 \times$ 
secretory granules (Fig. 2c). Some of these were antiLHRH positive by immunohistochemistry (Fig. $2 \mathrm{~d}$, e). Some axons of diabetic animals contained antiLHRH positive granules which appeared to fuse and partially disintegrate (Fig. 2f). Positive material was also present in the vesicles. It was seldom in granules and generally mixed with cell debris (Fig. $2 \mathrm{~g}, \mathrm{~h}$ ).

\section{Pituitary}

By light microscopic study of Toluidine blue stained semi-thin sections, typical LH-gonadotrophs were readily found in control animals but practically absent in diabetics.

By examination of immunohistochemically stained semi-thin sections, cells staining positively for LH were found in all control rats. These cells corresponded in number and size to the above described LH-gonadotrophs. The positive material consisted of few peripherally located secretory granules and of centrally located droplets (Fig. 3 a). In diabetic animals cells with similar characteristics were rare and numerous smaller cells filled with granules staining positively for $\mathrm{LH}$ were found (Fig. $3 \mathrm{~b}$ ).

By electron microscopy, typical LH-gonadotrophs (Fig. $3 \mathrm{c}$ ) were seen in all control rats. Secretory granules were normal. The endoplasmic reticulum was dilated and its cisternae were filled by finely granular material. Lysosomes were rare. Diabetic animals had extremely few typical LH-gonadotrophs. Smaller cells, packed with secretory granules comparable in size and shape with LH granules (Fig. 3d) and positively staining for $\mathrm{LH}$ by electron microscopic immunohistochemistry were frequent (Fig. $3 \mathrm{e}, \mathrm{f}$ ). In these cells endoplasmic reticulum was poorly developed and lysosomes were numerous.

\section{Testis}

In control animals the testicular weight (Table 1) was $3.70 \pm 0.06 \mathrm{~g}$ (mean $\pm \mathrm{SEM}$ ). In the diabetics it was reduced significantly to $2.79 \pm 0.19(p<0.01)$. Individual differences were relatively small in controls, but about three times as large in diabetics (Table 1).

The microscopic study of semi-thin sections of testes revealed in diabetic animals high individual differences also in the degree of histopathological change. The testes with the highest weights did not appreciably differ from those of control animals and had normal tubules. Spermatogenesis was complete. The testes with the lowest weights had tubules with a markedly reduced diameter. Spermatogenesis was generally blocked at spermiocyte I/II stage and premature sloughing was frequent. Leydig cells were few and reduced in size.
Electron microscopically, the Leydig cells of control animals contained abundant secretory material. In the severely affected testes of diabetic animals the Leydig cells were highly reduced in number and showed signs of degeneration.

\section{Discussion}

Our results, after diabetes of 12 month duration, are comparable with those obtained by Oksanen [7] after 4 months of disease. Both testicular weights and severity of the histological changes varied within a wide range among individuals, although all diabetic rats had comparably high blood glucose levels and low body weights. Also the increased duration of the disease did not enhance severity and frequency of the testicular lesions.

Leydig cells were extremely rare in severely affected testes. The few remaining cells underwent similar but more severe changes than those reported by Orth et al. [8].

Different explanations have been offered in an attempt to clarify the pathogenesis of diabetic testicular lesions [7], but in more recent years attention has been focussed on the mechanism of impaired gonadotrophic function resulting from the dysfunction in gonadotropin releasing hormone secretion $[3,4,8-10]$.

Reports suggesting malfunction of the hypothalamus-pituitary system were generally based on indirect evidence, i. e. biochemical determinations of hormonal levels in blood $[3,4,9]$ or tissue extracts $[3,10]$.

Our experiments demonstrate by direct morphological methods that changes in the hypothalamus and pituitary are probably responsible for the testicular lesions.

The pituitary change observed in diabetic animals suggests that the secretory activity of LH-gonadotrophs is relatively more inhibited than the synthesis of new hormone. This may eventually lead to accumulation of secretory granules, partial crinophagy of unreleased hormone and involution of both the rough endoplasmic reticulum and the Golgi system. As a consequence, LH-gonadotrophs appear smaller, increased in number, and packed with secretory granules. Our observations may explain the reduced LH blood levels $[3,4,10]$ and increased LH content in the pituitary tissue $[3,4]$ of diabetic rats.

The immunohistochemical demonstration of comparable amounts of LHRH in the hypothalamus of both control and diabetic animals corresponds to the finding of Paz et al. [10]. These authors [10] as well as Howland and Zebrowski [4] also found that LH blood levels of diabetic animals could be significantly raised by exogenous $\mathrm{LHRH}$. 
Our finding of morphologically abnormal neurohormone granules in otherwise normal axons and of vesicles containing large amounts of LHRH positive material in the arcuate nucleus and in the median eminence may represent the structural counterpart of the neuroendocrine impairment. The individual variations in the degree of hypothalamic change, as previously reported [1] and presently immunohistochemically confirmed, may determine the great variability of the testicular lesions.

The specific mechanism for the observed LHRH accumulation is not known. It might involve alterations in intrinsic neuronal functions or in LHRH release at the axon terminal or yet at other levels. Van Houten et al. [2] presented evidence of specific binding sites for blood-borne insulin in axons and axon terminals in the external median eminence and in the arcuate nucleus of the rat. Thus insulin may influence hypothalamic circuits regulating energy balance and hypophyseal function by modifying synaptic mechanisms.

In conclusion, our results demonstrate the morphological changes in the hypothalamic-hypophyseal system which appear to be responsible for the testicular lesions observed in diabetes mellitus, at least as it occurs in the streptozotocin-rat model.

Acknowledgements. This study was supported by the Schweizer Nationalfonds grant No. 3.198-0.77. We thank Miss D. Probst, Mrs. M. Balta and Mr. G. Di Lullo for their technical assistance.

\section{References}

1. Bestetti G, Rossi GL (1980) Hypothalamic lesions in rats with long-term streptozotocin-induced diabetes mellitus. Acta Neuropathol 52: 119-127

2. van Houten M, Posner BI, Kopriwa BM, Brawer JR (1980) Insulin binding sites localized to nerve terminals in rat median eminence and arcuate nucleus. Science 207: 1081-1083

3. Howland BE, Zebrowski EJ (1976) Some effects of experimentally-induced diabetes on pituitary-testicular relationships in rats. Horm Metab Res 8: 465-469
4. Howland BE, Zebrowski EJ (1980) Pituitary response to gonadotropin-releasing hormone in diabetic male rats. Experientia 36:610-611

5. Hunt EL, Bailey DW (1961) The effects of alloxan diabetes on the reproductive system of young male rats. Acta Endocrinol $38: 432-440$

6. Mayor HD, Hampton JC, Rosario B (1961) A Simple method for removing the resin from epoxy-embedded tissue. J Biophys Biochem Cytol 9:909-910

7. Oksanen A (1975) Testicular lesions of streptozotocin diabetic rats. Horm Res 6: 138-144

8. Orth JM, Murray FT, Bardin CW (1979) Ultrastructural changes in Leydig cells of streptozotocin-induced diabetic rats. Anat Rec 195: 415-429

9. Paz G, Homonnai ZT (1979) Leydig cell function in streptozotocin-induced diabetic rats. Experientia 35: 1412-1413

10. Paz (Frenkel) G, Homonnai ZT, Drasnin N, Sofer A, Kaplan R, Kraicer PF (1978) Fertility of the streptozotocin-diabetic male rat. Andrologia 10: 127-136

11. Rossi GL (1975) Simple apparatus for perfusion fixation for electron microscopy. Experientia 31: 998-999

12. Rossi GL, Meister V, Waber S (1980) Hodenveränderungen bei Ratten mit Streptozotocin-induziertem Diabetes. Schweiz Med Wochenschr 110:782

13. Rossi GL, Probst D, Panerai AE, Cocchi D, Locatelli V, Müller EE (1979) Ultrastructure of somatotrophs of rats with median eminence lesions: Studies in basal conditions and after thyrotropin-releasing hormone stimulation. Neuroendocrinology 29: $100-109$

14. Schöffling K, Federlin K, Schmitt W, Pfeiffer EF (1967) Histometric investigations on the testicular tissue of rats with alloxan diabetes and Chinese hamsters with spontaneous diabetes. Acta Endocrinol 54: 335-346

15. Sternberger LA, Hardy PH, Cuculus JJ, Meyer HG (1970) The unlabeled antibody-enzyme method of immunohistochemistry. Preparation and properties of soluble antigen-antibody complex (horseradish peroxidase-antihorseradish peroxidase) and its use in identification of spirochetes. J Histochem Cytochem 18:315-333

Received: 24 March 1981

and in revised form: June 1981

G. L. Rossi, M. D.

Institut für Tierpathologie

Universität Bern

Postfach 2735

CH-3001 Bern, Switzerland 